\title{
Volunteering Tourism and Sustainable Development: A Case Study of an Andean Indigenous Project: Quilla Pacari, Chimborazo
}

\author{
Luis Salcedo, Luis Quevedo* (i) \\ Universidad Nacional de Chimborazo UNACH, Riobamba, Ecuador \\ Email: *luis.quevedo@unach.edu.ec
}

How to cite this paper: Salcedo, L. and Quevedo, L. (2021) Volunteering Tourism and Sustainable Development: A Case Study of an Andean Indigenous Project: Quilla Pacari, Chimborazo. Open Journal of Ecology, 11, 596-609.

https://doi.org/10.4236/oje.2021.119038

Received: July 23, 2021

Accepted: August 31, 2021

Published: September 3, 2021

Copyright $\odot 2021$ by author(s) and Scientific Research Publishing Inc. This work is licensed under the Creative Commons Attribution International License (CC BY 4.0).

http://creativecommons.org/licenses/by/4.0/

\begin{abstract}
Volunteering tourism incorporates services and activities related to the caring of environmental, cultural, or humanitarian issues, intending to benefit not only tourists but also locals. Therefore, this activity fits into principles of sustainable development which has been defined as growth based on a balance between the environmental, social, and economic dimensions. The aim of this study was to determine the contribution of volunteering tourism to sustainable development and to identify the crucial factors to implement a successful volunteering project. We explored the interactions between volunteering tourism and sustainable development through a qualitative approach considering as case study: the rural tourism project "Quilla Pacari", located in the highlands of Chimborazo province, Ecuador. Our findings proportionate information about the influence of volunteering tourism in principles associated with sustainable development revealing a general insight into the interactions and identifying the perception about the crucial factors to implement a successful volunteering project. However, the Quilla Pacari project located in Chimborazo province is relatively emergent and further studies are needed to clarify all the relations associated with the process.
\end{abstract}

\section{Keywords}

Sustainable Tourism, Volunteering Tourism, Andean Project, Chimborazo, Quilla Pacari

\section{Introduction}

Sustainable Development has been defined by the Commission Brundtland [1] as a paradigm that proposes to satisfy the actual needs without compromising 
the possibility of future generations to accomplish their own needs. This definition has been widely accepted and several studies have included sustainability and its interactions, however, a common perspective is an analysis through its dimensions: environmental, socio-cultural, and economic [2] [3] [4] [5] [6]. These three dimensions have been identified as fundamental components of sustainability and their participation in a sustainable system has been described through the following statements: 1) An efficient system should produce goods and services, maintaining a good level of governance and a limited external debt, to avoid extreme economic inequalities (Economic sustainability). 2) A system based on environmental sustainability should avoid overexploitation of renewable resources systems, and consuming responsibly nonrenewable resources at the time that it is investing to find suitable substitutes. This includes the care of all ecosystem services associated with biodiversity (Environmental sustainability). 3) A system should achieve equality in the provision of social services as health and education, generating gender equity, and adequate opportunities and participation ( $\mathrm{So}$ cial sustainability) [7].

Nowadays, it is imperious that the shift is towards a sustainable development paradigm [8] to revert the deterioration of the life-supporting ecosystems, providing additional efforts to their regeneration. In that sense, tourism has been identified as an important driver to promote the sustainable development of territories by several international agreements: In 1980, the World Conservation Strategy, the Brandt Commission Report, and World Tourism Organization Manila Declaration; in 1982, the UNEP/WTO Accord; in 1987 the Brundtland Report, and in 1992, the United Nations Conference on Environment and Development (UNCED-Earth Summit). In this context, sustainable tourism has been defined by the UN World Tourism Organization as a kind of tourism that satisfies the needs of tourists and hosts in the present while protects and provides opportunities for the future. Sustainable tourism looks to maintain the social and economic compensations at the same time that the undesirable impacts on the natural, historic, cultural, or social environment are reduced or mitigated. In fact, when it is compared with other economic activities, tourism shows a stronger relationship with the society and environment, due in part to its dependency on preserved environments, cultural particularities, and social interactions. The practice of conscious tourism will contribute significantly to the sustainability of societies [9] [10] [11].

In the Andean region, it is possible to find rural areas located in mountainous places with low population density but with an important cultural heritage [12], which is not always well known [13]. In this context, the traditional paradigm of development is no longer functional [14] [15] and the notion of sustainability becomes applicable and effective, especially in a global context where there is an increasing number of tourists looking for alternatives that include experiences based on the contact with local people appreciating the landscape and culture of the territory [16] under principles of sustainability [4] which is a key element to 
promote a genuine interaction between locals and tourists [17] [18] [19]. One of these alternatives is volunteering tourism, which has been defined as an activity that incorporates services and activities related to the caring of environmental, cultural, or humanitarian issues, intending to benefit not only tourists but also locals [20]. Volunteering tourism satisfies the needs of tourists who want to "travel with a purpose" [21] and "make a difference during their holidays" [22], enjoying a tourist experience with the benefit of contributing to others. This kind of experience is usually developed not in areas considered as major tourist destinations but in locations near to protected natural areas or rural regions. Volunteer tourists have been defined as people who invest their time, budgets, and manpower at a destination far from home to gain cultural, environmental, and spiritual experiences [23]. Besides, volunteering has been recognized as an activity with a significant role to play in achieving the United Nations Sustainable Development Goals [24].

Nowadays, there are several programs offered by wide sources, such as government agencies, indigenous communities, non-governmental organizations, tour operators, and academic institutions [25] [26] [27]. Although the content of their projects may be considered similar because includes: volunteer and tourism as main elements, their goals and missions can vary widely. For example, some programs emphasize touristic activities, while others include more volunteer services. So, volunteering programs may target young people, mature adults, families, unskilled laborers, students, or professionals; and, the duration of a trip may vary from less than a week to months or even years [20]. The concept of volunteer tourism includes a great diversity of projects and a wide spectrum of volunteer tourists, which have shown a great breadth of motivations [23]. These motivations include altruism, travel and adventure, personal growth, cultural exchange and learning, professional development, organization goal or mission, and right time or place [20] [28].

Ecuador is a small Andean country that occupies an area of $256.370 \mathrm{~km}^{2}$ and has about 17 million inhabitants. It shares borders in the north with Colombia, in the south and east with Peru, and in the west with the Pacific Ocean. Ecuador has been identified as one of the most diverse countries per square kilometer in the world. However, the applications of initiatives that promote sustainable tourism are still few and volunteering tourism could become a viable alternative.

\section{Study Area}

The Chimborazo province (Figure 1 ) is located in the center of the inter-Andean region of Ecuador, at $1^{\circ} 40^{\prime} 00^{\prime \prime S} 78^{\circ} 39^{\prime} 00^{\prime \prime O}$ coordinates. Its geomorphology includes several large mountains and volcanoes (Chimborazo, Carihuayrazo, Altar, Igualata, Tungurahua, Sangay) some of them sharing territory with other provinces. Chimborazo occupies a territory of about $5.999 \mathrm{~km}^{2}$, where inhabits 524.004 people. Its territory has a wide altitudinal gradient (100 - 6.263 m.a.s.l.) and it is characterized for presenting a climatic heterogeneity where is possible 


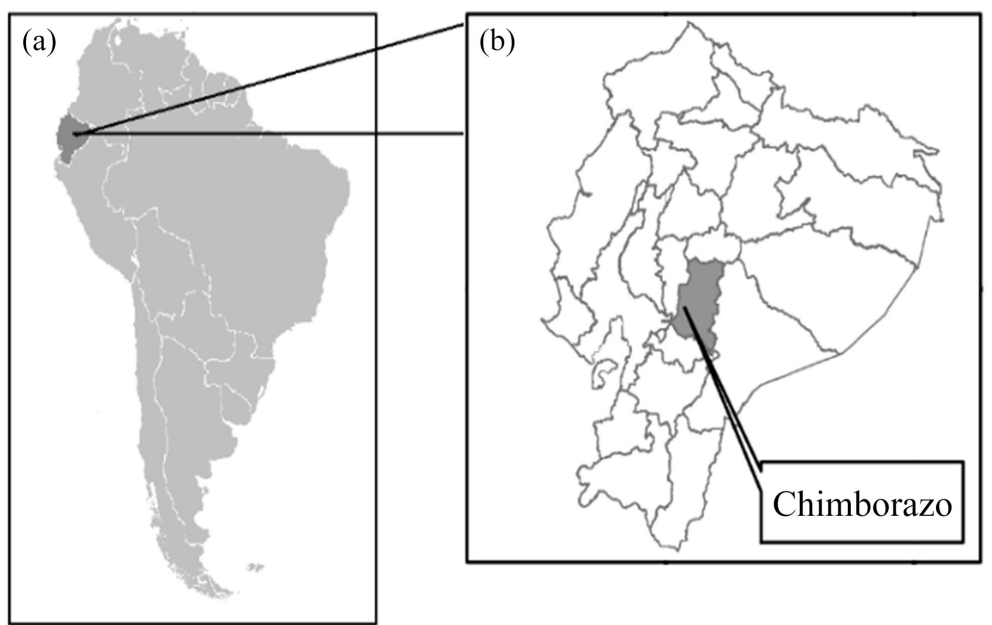

Figure 1. Location of the study area. (a) Ecuador in South America; (b) Chimborazo province in Ecuador.

to find: glacial (above 4600 m.a.s.l.), moorland (between 3000 and 4000 m.a.s.l.), mesothermic dry climate (down to 2000 m.a.s.l.). It is possible to access the province by first-order routes from the main cities of Ecuador as Quito or Guayaquil. The name of the province is due to the presence of Chimborazo volcano, which is the highest mountain in Ecuador with 6.263 meters above sea level. Due to terrestrial rotation, the diameter in the equatorial zone is the largest on the entire planet. Therefore, if the distance from the center of the Earth is measured, the Chimborazo summit is the most distant point, exceeding by more than two kilometers the Everest, which is the highest altitude mountain above sea level.

Administratively, Chimborazo province has 10 cantons (Alausí, Chambo, $\mathrm{Cu}-$ mandá, Penipe, Colta, Riobamba, Guamote, Chunchi, Pallatanga and Guano) and 45 rural parishes. One of these parishes is Calpi where is located a small touristic project: Quilla Pacari, which means "the moon awakening". The project was started by 80 women associated to dynamize the local economy and promote intercultural exchange.

\section{Methodology}

The study was developed through a qualitative approach to explore the interactions between volunteering tourism and sustainable development, qualitative methods have been previously utilized in several studies related to volunteering tourism [20] [21] [29] [30] [31]. We used a methodology of case studies [32] [33] which has been commonly applied in social sciences to approach the comprehension of specific questions adding elements that contribute to identifying and understanding the relation between events.

This work aimed to assess the contribution of volunteering tourism to sustainable development and to identify the crucial factors to implement a successful volunteering project, by the analysis of the context of a rural tourism project: Quilla Pacari, located in the highlands of Chimborazo province-Ecuador. 
We considered the importance of involving different groups of stakeholders [34] from an integrative perspective which assumes that an effective organization analysis requires consensus from a plurality of key stakeholders [35]. So, Table 1 presents a core of key stakeholders identified and the number of interviews carried out for each group. A total of 86 interviews were conducted from January to June 2021.

The questions that we used in the interviews were designed with the aim of 1) to assess the contribution of volunteering tourism to sustainable development, and 2) to identify the crucial factors to implement a successful volunteering project.

To assess the contribution of volunteering tourism to sustainable development, we used 3 dimensions including 12 accepted principles of sustainable tourism development (Table 2), which were developed [36] according to the methodology presented by the United Nations Environment Program and the World Tourism Organization [37] physical integrity, biological diversity, resource efficiency, environmental purity, cultural richness, community wellbeing, local control, visitor fulfillment, social equity, employment quality, local prosperity, and economic viability. The level of volunteering tourism contribution to each indicator was determined with a four-point licker scale the following scale of values: $0=$ Null $1=$ Low 2 = Medium 3 = High.

To identify the crucial factors to implement a successful volunteering project, we proposed 3 dimensions (Organizations, Volunteer-tourists and, Host communities) each of them including three factors (Table 3): product design, management, promotion, altruism, life-changing experience, skills, organizational strengthening, economic benefits and, cultural interchange. The perception about the magnitude of importance of each factor was determined with a four-point licker scale the following scale of values: $0=\operatorname{Null} 1=$ Low $2=$ Medium $3=$ High .

Table 1. Key stakeholders and number of interviews.

\begin{tabular}{cc}
\hline Stakeholder group & Interviews (number) \\
Ministry of Tourism of Ecuador & 8 \\
Ministry of Environment of Ecuador & 8 \\
Government of the Chimborazo province & 8 \\
Government of the Riobamba canton & 8 \\
Universidad Nacional de Chimborazo & 8 \\
Escuela Superior Politécnica de Chimborazo & 12 \\
ONG's & 14 \\
Quilla Pacari project & 14 \\
Volunteers &
\end{tabular}


Table 2. Indicators of sustainability.

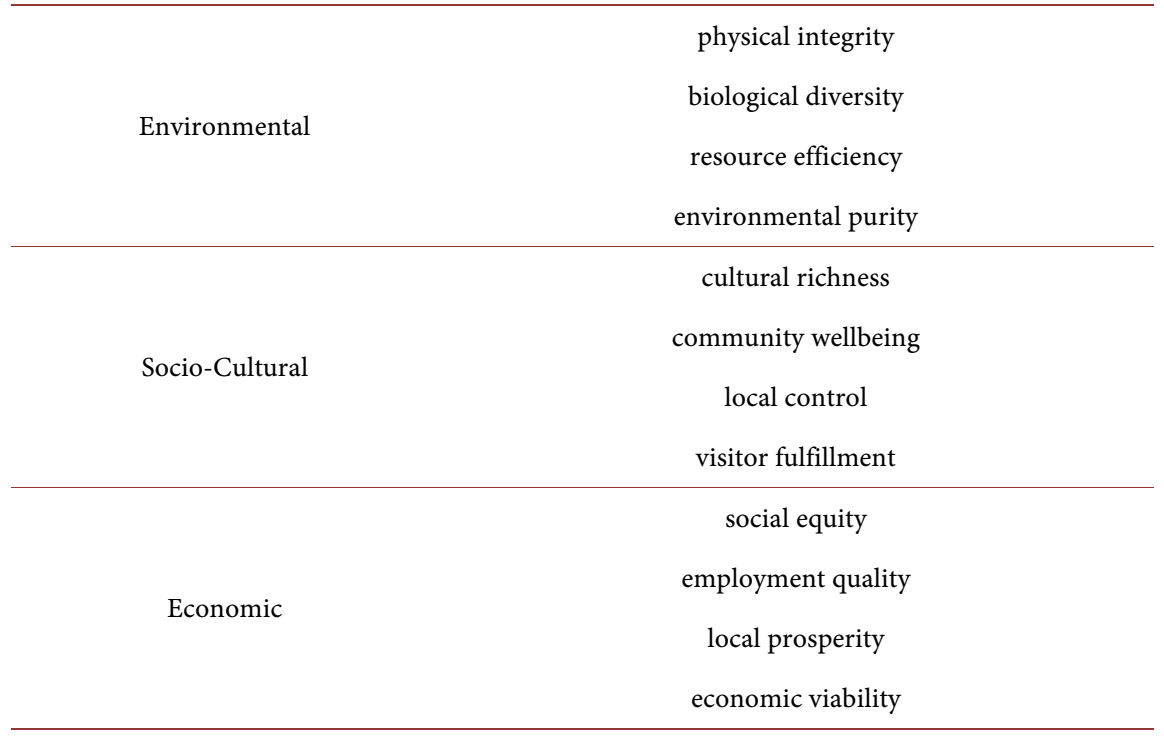

Table 3. Crucial factors to implement a volunteering project.

\begin{tabular}{cc}
\hline Organizations & Product design \\
& Management \\
Promotion
\end{tabular}

\section{Results and Discussion}

\subsection{Contribution of Volunteering Tourism to Sustainable Development}

The contribution of volunteering tourism to indicators of sustainability is presented in Figure 2.

\subsubsection{Environmental Dimension}

The principle of physical integrity is related to the conservation of urban and rural landscapes, avoiding an environmental degradation of ecosystems, and volunteering tourism presented a low level (1) of influence in this aspect. The biological diversity which is related to the support to the preservation of natural ecosystems and wildlife, minimizing the damages to these habitats showed a medium level (2) of influence. The resource efficiency focuses in diminish the use of scarce and non-renewable resources during the operation and development of tourism services and facilities, reflex a low level of influence (1) in the same way 


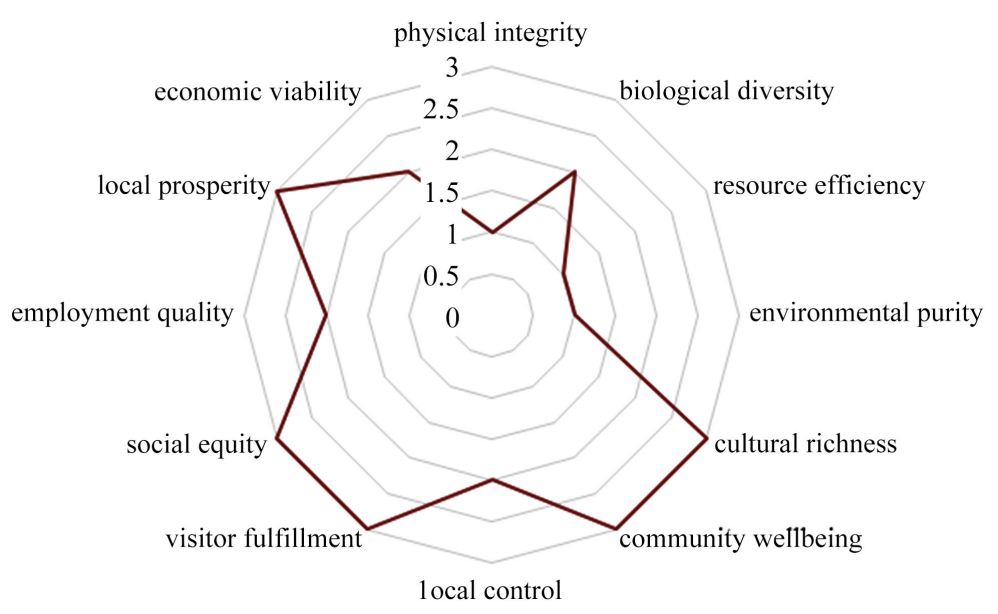

Figure 2. Volunteering tourism contribution to indicators of sustainability. Level of contribution: $0=$ Null $1=$ Low $2=$ Medium $3=$ High .

that the environmental purity principle that looks for minimizing the contamination of air, water, and soil and reduce the generation of waste caused by tourism activities. These results demonstrate a clear perception of the stakeholders about how volunteering tourism support and enhance environmental sustainability and in general, considers this activity as one based on environmental friendliness. A link between diversity, volunteering tourism, and sustainable development was found in the analysis of our results, which could be related to the fact that volunteering tourists are motivated for the possibility of enjoying the landscape, flora, and fauna of the Chimborazo province where tourism activities are mostly based on environmental resources. They enjoy activities that include interactions with nature, biodiversity, and unspoiled environments located far away from conglomeration and pollution. This kind of tourist is looking for sustainable options that promote environmental protection and the maintenance of diversity. However, there are facilities and activities associated with volunteering tourism that can be considered anthropogenic alterations on the highlands ecosystems of the Chimborazo province.

\subsubsection{Socio-Cultural Dimension}

The cultural richness which is associated with the respect of the historic heritage, traditions, culture, and singularity of hosting communities, presented a high level (3) of influence, in the same way that the community wellbeing principle which focuses in to preserve and supports the life quality in local communities, including the existence of social organizations and the free and open access to resources, services, and ecosystems, avoiding their degradation. The local control related to involve and empower hosting communities in development planning, taking an active role in the decision making for the development and management of tourism in the zone, showed a medium level (2) of influence. And the visitor fulfillment which focuses on making available a safe, satisfying, and fulfilling experience for tourists, creating an experience free of discrimination (by gender, race, disability, or in other ways), obtained a high (3) level of influence. These values 
demonstrate that cultural richness has a strong link with sustainable development, which could be explained by the presence of an important cultural heritage in the study area, being also an element of social cohesion between the inhabitants of the local communities. Volunteering tourists identify the presence of indigenous communities and the culture associated with them as very important elements when they select a host project. On the other hand, the volunteers have been identified by the community members as respectful people interested in cultural interchange with the host communities, and as a source of new ideas that contribute to the growth of the project. An adequate practice of volunteering tourism allows the protection of the cultural richness without affecting it, but some regulations [31] to the development must be suggested to achieve effective protection to the culture when touristic activities are implemented. There is a strong perception of stakeholders about the contribution of volunteering tourism enhancing the organization of local communities and promoting participation in planning and development programs. Some volunteers have supported the linking with international cooperation institutions.

\subsubsection{Economic Dimension}

The principle of social equity, which seeks for extensive and fair distribution of the benefits (economics and socials) derivate from volunteering tourism to the hosting community, including the improvement of opportunities, the increasing of incomes, and the availability of services, obtained a high value (3) of influence. While, the employment quality that looks for enhancing the existence of local jobs linked with tourism, the level of incomings, work conditions, and the availability to all people without any kind of discrimination, obtained a medium value (2) of influence. The local prosperity principle focused on the contribution of volunteering tourism to the economic prosperity of the local community, including the amount of the visitor spending that is retained by the local people, presented a high value (3) of influence. Finally, the economic viability principle, which is related with ensure the feasibility and competitiveness of destinations and tourism business, giving the conditions to be able to continue and prosper in the time, which will produce benefits in the long term, showed a medium value (2) of influence. These results evidence a strong perception of stakeholders about the economic viability of the volunteering tourism projects and the generation of employees under fair conditions. Even when tourism is strongly perceived as a driver to achieve sustainable development, the way to successfully implement networks and connect with international markets seems to be unclear. The indigenous communities demand support policies and governmental incentives to develop touristic projects associated with volunteering.

\subsection{Crucial Factors to Implement a Successful Volunteering Project}

The perception about the magnitude of importance of each factor to implement a successful volunteering project is presented in Figure 3. 


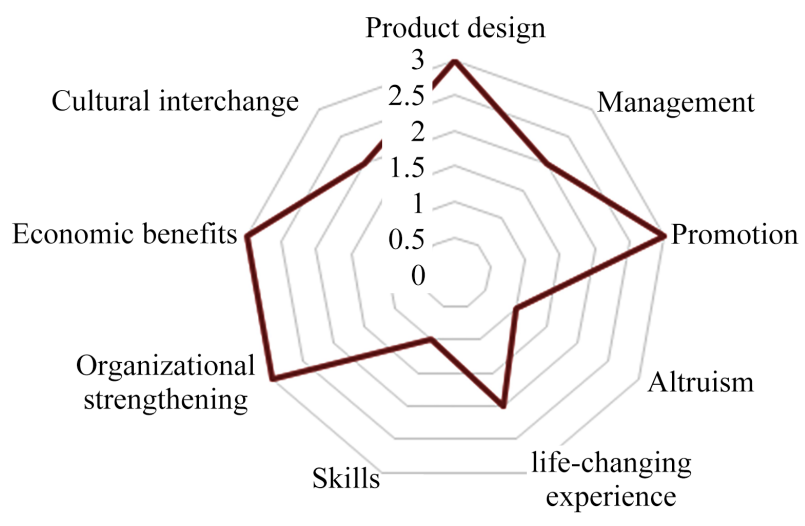

Figure 3. Crucial factors to implement a successful volunteering project. Level of importance: $0=$ Null $1=$ Low $2=$ Medium $3=$ High.

\subsubsection{Organizations}

The product design which is a factor related to the type of volunteering experience that will be offered and include the type of work involved and the environment in which it will be performed; presented a high level (3) of importance. While, the Management that involves activities as recruitment, scheduling, and controlling the volunteering process to accomplish desired goals, showed a medium level (2) of importance. Finally, the promotion focuses on activities destined to developing communications campaigns that reach and motivate volunteers to involve in the project, reflexed a high level (3) of importance. These findings demonstrate that product design requires considering whether the experience being offered matches the needs of volunteers. So, given that the needs of different segments can vary significantly, the appropriate product offering for each segment should be deeply analyzed and, if it is possible, customize the experience to match it with volunteer needs. In this sense, an organization should include in its planning, strategies to keep the volunteers participating for as long as possible [38], through the implementation of an effective process for recruiting, providing continuous training, support and recognition/rewards for volunteers and, maintaining well-documented policies and procedures that provide structure for the volunteer work environment.

\subsubsection{Volunteer-Tourist}

The altruism that involves acting out of concern for the well-being of other people, in this case, the host community members, showed a low level (1) of importance. While, life-changing experience related to how a volunteering experience could alter the lives or circumstances of the participants in a substantial way, presented a medium value (2) of importance. And skills focused on the possibility that the volunteering experience allows learning new abilities, obtained a low level (1) of importance. Volunteers are not one homogeneous group. In fact, many kinds of people with diverse backgrounds, skills, and experiences are involved in volunteering programs, and they do so for myriad reasons. Their diverse range of skills and willingness to volunteer has been recognized as a highly valuable potential, particularly in terms of providing support for rural communities where volun- 
teering resources are more limited [39].

\subsubsection{Host Communities}

The organizational strengthening related to the community's wish to develop or improve existing systems and processes showed a high level (3) of importance; in the same way that the economic benefits focused on the income generated by the volunteering program to the host community. While, the cultural interchange that looks for sharing ideas, traditions, and knowledge with volunteers who come from a completely different background, presented a medium level (2) of importance. When the interactions between the host community members and volunteers flow, it provides the opportunity to learn new skills for both sides. Volunteers benefit the host community by providing new insights, increasing effectiveness and volume of operations, and enhancing the image of the organization [40]; while, the volunteer trip has the power to change the volunteer life. It is a win-win situation for all parties involved.

\section{Conclusions}

Our findings obtained through the case study of Quilla Pacari project allow us to conclude that volunteering tourism promotes sustainable development in the Chimborazo province and also, we have identified the perception about the crucial factors to implement a successful volunteering project.

Volunteers are highly motivated to visit the Chimborazo province due to its richness in landscapes, biodiversity and, culture. Therefore, the implementation and support of touristic projects based on sustainability principles are necessary to guarantee the well-being of local communities. In this sense, the three dimensions of sustainability should be considered in a wide outlook for development. The environmental dimension could integrate the implementation of environmental protection programs with the active participation of the volunteers and the host community. The socio-cultural dimension could be enhanced by the implementation of programs based on mutual cultural appreciation to contributing to the protection of the cultural heritage and also guaranteeing the participation of local communities in the planning policies and strategies led by the local and national government. Finally, the economic dimension could be supported by actions to improve the life quality in local communities that have included volunteering tourism as a strong option for their economic growth. Volunteering tourism will empower local communities to create feasibility business associated with the touristic activity enabling the creation of new job opportunities under fair conditions. Nowadays, volunteers are interested in sustainable options that allow them to enjoy and preserve the environment simultaneously. Therefore, volunteering programs provide an excellent context where people tend to appreciate landscapes, local agriculture, and culture, which is a common factor in projects developed in a context of nature [5].

Globally, volunteering tourism is seen as a sustainable activity and it is constantly growing [41] [42] [43], and in Ecuador, the rural areas are located in an 
extraordinary position [13] that could enhance the implantation of these kinds of projects. In fact, when volunteering is conceived through the prism of leisure it has demonstrated cross-cultural applicability [44]. Additionally, volunteering activities offer the possibility of dynamizing the economy of local people through associated services as guide tours, shops, souvenirs, accommodations, food \& beverage locals among others.

However, a high-quality volunteering experience necessarily involves good management practices at the organizational level [45]. So, the design of a volunteering program as a product requires to consider that the experience being offered matches to the needs of volunteers, and as the needs of different segments can widely vary, the appropriate product for each segment should be deeply analyzed and communicated through a promotional strategy developed concerning specific motivations, improving in that way the effectiveness of marketing efforts [46] [47] [48]. Additionally, an effective volunteering project should develop strategies (training, support, recognition, rewards) to keep the volunteers loyal [38] [45]

We think that this study could contribute to further understanding of the role of volunteering tourism as a strategic asset for sustainable development under its dimensions (economic, socio-cultural, and environmental). Our findings proportionate information about the influence of volunteering tourism in principles associated with sustainable development revealing a general insight into the interactions. However, the Quilla Pacari project located in Chimborazo province is relatively emergent and is under growing and further studies are needed to clarify all the relations associated with the process.

\section{Conflicts of Interest}

The authors declare no conflicts of interest regarding the publication of this paper.

\section{References}

[1] Brundtland Commission (1987) World Commission on Environment and Development (WCED): Our Common Future. The United Nations General Assembly, New York, 318.

[2] Chhabra, D. (2010) Sustainable Marketing of Cultural and Heritage Tourism. Routledge, London. https://doi.org/10.4324/9780203855416

[3] Knox, P. and Mayer, H. (2013) Small Town Sustainability: Economic, Social, and Environmental Innovation. Walter de Gruyter, Basel.

[4] Richins, H. (2009) Environmental, Cultural, Economic and Socio-Community Sustainability: A Framework for Sustainable Tourism in Resort Destinations. Environment, Development and Sustainability, 11, 785-800. https://doi.org/10.1007/s10668-008-9143-6

[5] Sitarz, D. (Ed.) (1993) Agenda 21: The Earth Summit Strategy to Save Our Planet. Colorado, Boulder Earth Press.

[6] UNWTO (United Nations World Tourism Organization) (2014) World Tourism Organization Annual Report 2013. United Nations World Tourism Organization, Ma- 
drid.

[7] Harris, J.M. (2003) Sustainability and Sustainable Development. International Society for Ecological Economics, 1, 1-12.

[8] de Oliveira, J.F.G. and Trindade, T.C.G. (2018) Sustainability Indicators. In: Sustainability Performance Evaluation of Renewable Energy Sources: The Case of Brazil, Springer International Publishing, Cham, 45-62. https://doi.org/10.1007/978-3-319-77607-1_3

[9] Office for National Statistics (2011) Sustainable Tourism: A Review of Indicators. Economic \& Labour Market Review, 5, 77-95. https://doi.org/10.1057/elmr.2011.98

[10] Streimikiene, D., Svagzdiene, B., Jasinskas, E. and Simanavicius, A. (2021) Sustainable Tourism Development and Competitiveness: The Systematic Literature Review. Sustainable Development, 29, 259-271. https://doi.org/10.1002/sd.2133

[11] Mathew, P.V. and Nimmi, P.M (2021) Sustainable Tourism Development: Discerning the Impact of Responsible Tourism on Community Well-Being. Journal of Hospitality and Tourism Insights. https://doi.org/10.1108/JHTI-02-2021-0052

[12] Gabriel-Campos, E., Werner-Masters, K., Cordova-Buiza, F. and Paucar-Caceres, A. (2021) Community Eco-Tourism in Rural Peru: Resilience and Adaptive Capacities to the Covid-19 Pandemic and Climate Change. Journal of Hospitality and Tourism Management, 48, 416-427. https://doi.org/10.1016/j.jhtm.2021.07.016

[13] Quevedo, L., Cejas, M., Vinueza, P. and Castillo, D. (2020). Desde lo rural hacia lo urbano ¿puede el turismo ser el camino hacia el desarrollo? In: Editorial Centro de Estudios Sociales de América Latina, Ed, De lo rural a lo urbano en Ecuador, Editorial Centro de Estudios Sociales de América Latina, 236.

[14] Fonte, M. (2006) Slow Food's Presidia: What Do Small Producers Do with Big Retailers? In: Marsden, T. and Jonathan Murdoch, J., Eds., Research in Rural Sociology and Development, Vol. 12, Emerald Group Publishing Limited, Bingley, 203-240. https://doi.org/10.1016/S1057-1922(06)12009-0

[15] Gannon, A. (1998) Mastering Change: A New Paradigm in Building Positive Futures for Rural Communities. Proceedings of the Positive Rural Futures Conference, Biloela, 28-30 May 1998, 28-30.

[16] Chafe, Z. and Honey, M. (2005) Consumer Demand and Operator Support for Socially and Environmentally Responsible Tourism. Center on Ecotourism and Sustainable Development, Washington DC.

[17] Demirović, D., Radovanović, M., Petrović, M.D., Cimbaljević, M., Vuksanović, N. and Vuković, D.B. (2018) Environmental and Community Stability of a Mountain Destination: An Analysis of Residents' Perception. Sustainability, 10, Article No. 70. https://doi.org/10.3390/su10010070

[18] Pavione, E., Pezzetti, R. and Gazzola, P. (2017). The Role of "Slow Territories" in the Development of Sustainable Tourism. European Scientific Journal, 13, 238-248.

[19] Reisinger, Y. and Dimanche, F. (2010) International Tourism. Routledge, London and New York. https://doi.org/10.4324/9780080941288

[20] Chen, L.-J. and Chen, J.S. (2011) The Motivations and Expectations of International Volunteer Tourists: A Case Study of "Chinese Village Traditions". Tourism Management, 32, 435-442. https://doi.org/10.1016/j.tourman.2010.01.009

[21] Brown, S. (2005) Travelling with a Purpose: Understanding the Motives and Benefits of Volunteer Vacationers. Current Issues in Tourism, 8, 479-496.

https://doi.org/10.1080/13683500508668232

[22] Coghlan, A. (2006) Volunteer Tourism as an Emerging Trend or an Expansion of Eco- 
tourism? A Look at Potential Clients' Perceptions of Volunteer Tourism Organisations. International Journal of Nonprofit and Voluntary Sector Marketing, 11, 225 237. https://doi.org/10.1002/nvsm.35

[23] Wearing, S. (2001) Volunteer Tourism: Experiences That Make a Difference. Centre for Agriculture and Bioscience International, Wallingford.

https://doi.org/10.1079/9780851995335.0000

[24] Lockstone-Binney, L. and Ong, F. (2021) The Sustainable Development Goals: The Contribution of Tourism Volunteering. Journal of Sustainable Tourism, 1-17. https://doi.org/10.1080/09669582.2021.1919686

[25] Ellis, C. (2003) Participatory Environmental Research in Tourism: A Global View. Tourism Recreation Research, 28, 45-55. https://doi.org/10.1080/02508281.2003.11081416

[26] Pongponrat, K. (2021) University Volunteer Programs for Post-Disaster Recovery: The Case of Post-Tsunami Japan. Kasetsart Journal of Social Sciences, 42, 31-36. https://doi.org/10.34044/j.kjss.2021.42.1.05

[27] Baumann, A.C. (2021) Spaces for Encounters between Tourists and Locals in Times of Cruise Tourism and Overtourism. In: Carolin Lusby, Destination Unknown-Sustainable Travel and Ethical Tourism, University of Illinois Research Park, Champaign, IL, 3-14.

[28] Abreu, J. and Ferreira, M.R. (2021) What We Know about Volunteer Tourism-An Approach to Motivations and Impacts. International Journal of Sustainable Society, 13, 16-33. https://doi.org/10.1504/IJSSOC.2021.115676

[29] Caissie, L.T. and Halpenny, E.A. (2003) Volunteering for Nature: Motivations for Participating in a Biodiversity Conservation Volunteer Program. World Leisure Journal, 45, 38-50. https://doi.org/10.1080/04419057.2003.9674315

[30] Carter, K.A. (2008) Volunteer Tourism: An Exploration of the Perceptions and Experiences of Volunteer Tourists and the Role of Authenticity in Those Experiences. PhD Thesis, Lincoln University, Lincoln.

[31] McIntosh, A.J. and Zahra, A. (2007) A Cultural Encounter through Volunteer Tourism: Towards the Ideals of Sustainable Tourism? Journal of Sustainable Tourism, 15, 541-556. https://doi.org/10.2167/jost701.0

[32] Eisenhardt, K.M. (1989) Building Theories from Case Study Research. Academy of Management Review, 14, 532-550. https://doi.org/10.5465/amr.1989.4308385

[33] Yin, R.K. (2013) Case Study Research: Design and Methods. 5th Edition, SAGE Publications, Inc., Los Angeles.

[34] Mascarenhas, A., Nunes, L.M. and Ramos, T.B. (2015) Selection of Sustainability Indicators for Planning: Combining Stakeholders' Participation and Data Reduction Techniques. Journal of Cleaner Production, 92, 295-307. https://doi.org/10.1016/j.jclepro.2015.01.005

[35] Savage, G.T., Nix, T.W., Whitehead, C.J. and Blair, J.D. (1991) Strategies for Assessing and Managing Organizational Stakeholders. Academy of Management Perspectives, 5, 61-75. https://doi.org/10.5465/ame.1991.4274682

[36] Quevedo, L., Cejas, M., Vinueza, P. and Samaniego, W. (2020) Promoting Sustainable Development through Touristic MTB (Mountain Bike) Routes. The Experience of an Andean Region of Ecuador. Test Engineering and Management, 83, 2596825977.

[37] UN Environment Programme and World Trade Organization (2005) Making Tourism More Sustainable: A Guide for Policy Makers. UN Environment Programme, 
World Trade Organization, Geneva.

[38] Randle, M. and Dolnicar, S. (2009) Understanding the Australian Environmental Volunteering Market: A Basis for Behavioural Change and a Sustainable Future. Australasian Marketing Journal, 17, 192-203.

https://doi.org/10.1016\%2Fj.ausmj.2009.06.001

[39] Leonard, R. and Onyx, J. (2009) Volunteer Tourism: The Interests and Motivations of Grey Nomads. Annals of Leisure Research, 12, 315-332. https://doi.org/10.1080/11745398.2009.9686827

[40] Volunteering Australia (2016) State of Volunteering in Australia. Volunteering Australia, Australia.

[41] Ruhanen, L., Cooper, C. and Fayos-Solá, E. (2008) Volunteering Tourism Knowledge: A Case from the United Nations World Tourism Organization (UNWTO). In: Lyons, K., D. and Wearing, S., Eds., Journeys of Discovery in Volunteer Tourism: International Case Study Perspectives, CABI Publications, Wallingford, 25-35.

[42] Uriely, N., Reichel, A. and Ron, A. (2003) Volunteering in Tourism: Additional Thinking. Tourism Recreation Research, 28, 57-62.

https://doi.org/10.1080/02508281.2003.11081417

[43] Wearing, S.L. (2003) Volunteer Tourism. Tourism Recreation Research, 28, 3-4. https://doi.org/10.1080/02508281.2003.11081411

[44] Stebbins, R.A. and Graham, M. (2004) Volunteering as Leisure/Leisure as Volunteering: An International Assessment. Centre for Agriculture and Bioscience International, Wallingford.

[45] Smith, K. and Cordery, C.J. (2010) What Works? A Systematic Review of Research and Evaluation Literature on Encouragement and Support of Volunteering. A Systematic Review of Research and Evaluation Literature on Encouragement and Support of Volunteering (June 14, 2010). SSRN Electronic Journal. https://doi.org/10.2139/ssrn.1761655

[46] Clary, E.G., Snyder, M., Ridge, R.D., Miene, P.K. and Haugen, J.A. (1994) Matching Messages to Motives in Persuasion: A Functional Approach to Promoting Volunteerism. Journal of Applied Social Psychology, 24, 1129-1146. https://doi.org/10.1111/j.1559-1816.1994.tb01548.x

[47] Randle, M. and Dolnicar, S. (2012) Attracting Volunteers in Highly Multicultural Societies: A Marketing Challenge. Journal of Nonprofit \& Public Sector Marketing, 24, 351-369. https://doi.org/10.1080/10495142.2012.733668

[48] Randle, M. and Dolnicar, S. (2009) Does Cultural Background Affect Volunteering Behavior? Journal of Nonprofit \& Public Sector Marketing, 21, 225-247. https://doi.org/10.1080/10495140802529649 